\title{
Diagnóstico de outorgas de captação e lançamento de efluentes no Paraná e impactos dos usos insignificantes
}

\author{
Diagnosis of water abstraction and effluent discharge \\ licenses in Paraná and the impact of small uses
}

Camila Marin Stinghen ${ }^{1}$, Michael Mannich²

${ }^{1}$ Engenheira Ambiental, Departamento de Outorga e Fiscalização, Instituto das Águas do Paraná, Mestranda em
Engenharia Ambiental, Universidade Federal do Paraná - UFPR, Curitiba-PR, Brasil. E-mail:
cami.stinghen@gmail.com
${ }^{2}$ Professor Adjunto, Departamento de Engenharia Ambiental, Universidade Federal do Paraná - UFPR, Curitiba-PR,
Brasil. E-mail: mannich@ufpr.br

\begin{abstract}
Como citar: STINGHEN, C. M.; MANNICH, M. Diagnóstico de outorgas de captação e lançamento de efluentes no Paraná e impactos dos
\end{abstract} usos insignificantes. Revista de Gestão de Água da América Latina, v. 16, e10, 2019. https://dx.doi.org/10.21168/rega.v16e10.

RESUMO: A outorga de direito de uso dos recursos hídricos é uma ferramenta de controle quantitativo e qualitativo da água. Dentro desta ferramenta, alguns tipos de usos são caracterizados como insignificantes, e para tanto são dispensados de outorgas. No Paraná, as dispensas são conferidas aos usos com vazões inferiores ou iguais a $1,8 \mathrm{~m}^{3} / \mathrm{h}$. A partir dos dados públicos de outorga do Instituto das Águas do Paraná, realizou-se um diagnóstico das outorgas e dos usos insignificantes no estado e em grandes bacias hidrográficas. 0 diagnóstico mostrou ser um bom indicador econômico, caracterizando os diferentes usos da água em cada região paranaense. A influência dos usos considerados insignificantes em relação à vazão outorgável em bacias de pequeno porte no estado do Paraná revelou que a contribuição é inferior a 3\% em média. A gestão dos recursos hídricos no Paraná está adequada em relação ao tratamento dos usos insignificantes, não representando uma ameaça à disponibilidade dos recursos hídricos do estado do Paraná.

Palavras-chave: outorga, dispensa de outorga, usos insignificantes, gestão de recursos hídricos.

ABSTRACT: The granting license of water resources uses expresses the conditions for the use of water resources as a tool for quantitative and qualitative control of water. Some uses are characterized as insignificant, and are exempted from water license application (riparian water right). In Paraná State, our study area, the exemptions are granted to the uses with flow rates lower than or equal to $1,8 \mathrm{~m}^{3} / \mathrm{h}$. Based on the public data of the Instituto das Águas do Paraná, we did a diagnosis of those licenses and exemptions uses for the whole state and its larger basins. The diagnosis represents a good economic indicator, characterizing the different water uses in each region of Paraná. The insignificant uses corresponds on average to less than 3\% of the flow rate in small basins. Therefore, the water resources management in Paraná State is adequate considering the insignificant uses exempted from license and do not represent a threat to the availability of the water resources.

Keywords: water license, license exemption, insiginificant uses (riparian water right), water resources management.

\section{INTRODUÇÃO}

A outorga é um ato administrativo pelo qual o poder público expressa os termos e as condições de uso dos recursos hídricos, e que assegura o direito de todos de acesso a água (AGÊNCIA NACIONAL DE ÁGUAS, 2011). A outorga se aplica para quaisquer usos, fins, ou atividade que altere a qualidade e a quantidade do corpo hídrico, tanto superficial como subterrânea. Tal ato é um dos instrumentos previstos na Política Nacional de Recursos Hídricos, instituída pela Lei $n^{\circ} 9.433$ de 8 de janeiro de 1997, mais conhecida como Lei das Águas.

Recebido: 16 fev 2019. Revisado: 02 abr 2019. Aceito: 19 ago 2019. 
Em seu Art. 12, § 1, a Lei das Águas também estabelece que determinados tipos de uso independem de outorga, por utilizarem vazões pequenas, que são consideradas insignificantes. Essa classificação de uso dispensado de outorga, historicamente pode ser comparada a ideia dos direitos ripários, doutrina que já era desenvolvida no século XIX em regiões como Inglaterra e América do Norte. A doutrina ripariana sustentava que donos de terras ribeirinhas teriam o direito de fazer o uso "extraordinário" da água, com o compromisso de que a atividade não interferissem o direito de outros proprietários, a montante e a jusante. Entretanto o estabelecimento de limites para tais usos nunca foi uma tarefa simples. Cada esfera local de gestão de recursos hídricos atribui esses limites de acordo com as características e necessidades específicas, sejam eles definidos por tipologia de uso, por volume de água, ou até mesmo a inexistência de "usos livres" (HODGSON, 2006).

No Brasil, cada órgão gestor estadual tem autonomia para estabelecer os critérios e limites quanto a insignificância dos diferentes tipos de uso que o dispensam da outorga. Desta forma, as vazões de referência para as análises dos processos de outorgas bem como os limites definidos para concessão da dispensa de outorga variam entre os Estados da Federação, conforme apresentado na Tabela 1. Adicionalmente, as dispensas recebem cadastro e registro nos bancos de dados.

Os estados do Ceará, Paraíba e Sergipe, por exemplo, estabelecem como valor de referência para outorga a vazão regularizada anual com garantia de 90\%, a Q90\%. A Bahia também adota vazões com 90\% de permanência, entretanto essas são a nível diário (Q90\%). Já São Paulo e Minas Gerais utilizam a vazão média mínima de 7 dias consecutivos e 10 anos de período de retorno $\left(Q_{7,10}\right)$. Dos exemplos citados, Bahia, Minas Gerais, Paraíba, Sergipe e Ceará concedem dispensas de outorga apenas para captações diferentemente dos Estados de São Paulo e do Paraná, onde existem dispensa também para lançamento de efluentes.

Tabela 1 - Vazões de referência e de dispensa de outorga em diferentes Estados do Brasil.

\begin{tabular}{|c|c|c|}
\hline Estado & $\begin{array}{c}\text { Vazão de } \\
\text { Referência }\end{array}$ & $\begin{array}{c}\text { Vazão limite para } \\
\text { dispensas de outorga }\end{array}$ \\
\hline PR & $\mathrm{Q}_{95 \%}$ & $1,8 \mathrm{~m}^{3} / \mathrm{h}$ \\
\hline SP & $\mathrm{Q}_{7,10}$ & $1,04 \mathrm{~m}^{3} / \mathrm{h}$ \\
\hline $\mathrm{BA}$ & $Q_{90 \%}$ & 1,8 m³/h (Captação) \\
\hline MG & $\mathrm{Q}_{7,10}$ & $1,8 \mathrm{~m}^{3} / \mathrm{h}$ ou $3,6 \mathrm{~m}^{3} / \mathrm{h}$ (Captação) \\
\hline $\mathrm{CE}$ & $Q_{90 \%}$ anual & 2 m³/h (Captação) \\
\hline PB & $Q_{90 \%}$ anual & 2 m³/h (Captação) \\
\hline SE & $Q_{90 \%}$ anual & 2,5 m³/h (Captação) \\
\hline
\end{tabular}

FONTE: SEMA (SECRETARIA DE ESTADO DO MEIO AMBIENTE E RECURSOS HÍDRICOS, 2004); SÃO PAULO (2017); SRH

(SUPERINTENDÊNCIA DE RECURSOS HÍDRICOS DO ESTADO DA BAHIA, 2007); CERH (CONSELHO ESTADUAL DE RECURSOS

HÍDRICOS, 2004); Ceará (1994); Paraíba (1997), CONERH/SE (CONSELHO ESTADUAL DE RECURSOS HÍDRICOS DE SERGIPE, 2001).

Segundo a Resolução 39/2004 (SECRETARIA DE ESTADO DO MEIO AMBIENTE E RECURSOS HÍDRICOS, 2004), no Paraná, Estado que será o foco deste estudo, a vazão de referência adotada é a vazão natural com permanência de $95 \%$ do tempo (Q95\%), e é dispensada a outorga de captações individuais, ou lançamentos de efluentes em corpos d'água com vazão inferior ou igual a $1,8 \mathrm{~m}^{3} / \mathrm{h}$, equivalente a $0,5 \mathrm{~L} / \mathrm{s}$. Além disso, o somatório das captações insignificantes deve ser menor do que $20 \%$ da vazão outorgável no corpo hídrico. Caso contrário qualquer nova interferência na disponibilidade do corpo hídrico fica sujeita aos procedimentos de outorga. Para os lançamentos, a vazão necessária para diluição deve ser inferior a $50 \%$ da vazão de referência Q95\% para que esses usos sejam considerados insignificantes. A classificação como insignificante não exclui a responsabilidade do órgão gestor em computar e quantificar esses usuários nos balanços hídricos quali-quantitativos, uma vez que um conjunto de usos insignificantes pode tornar-se significativo (SILVA; MONTEIRO, 2003).

Nesse contexto, Marcolini (2016) identificou a existência de um déficit de estudos que avaliem os efeitos provocados pelos usos dispensados de outorgas em bacias de pequeno porte. Na ocasião, a autora avaliou as consequências da negligência por parte dos usuários e dos usos insignificantes (não autorizados) pelo do órgão gestor local, no Ribeirão Água Fria em Palmas (TO), que não suporta a demanda dos usuários autorizados, e que juntamente com as captações sem autorização ultrapassaram a disponibilidade hídrica do ribeirão, provocando conflitos de escassez de água.

São inúmeros os desafios encontrados no campo teórico, prático e operacional dos sistemas de gestão e emissão de outorgas, e a temática de 'outorga de uso da água' tem sido objeto crescente de 
diversos trabalhos. Entretanto, a preocupação é geralmente associada a estudos com proposições de aprimoramentos no gerenciamento das demandas e disponibilidades hídricas, amparados pela aplicação de metodologias e estratégias de gestão e alocação de água, para que sejam supridas todas as necessidades de uso evitando conflitos nas bacias (RIBEIRO; LANNA, 2003; VIEIRA, 2003; MACHADO; GALVÃO; SOUZA FILHO, 2012; SILVA; MONTEIRO, 2003; MOREIRA et al., 2014). Além disso, há uma busca sólida de novas ferramentas e modelos a serem incorporados às análises técnicas que tragam facilidade e maior confiabilidade na determinação de valores para as vazões de referência que são a base de definição das disponibilidades hídricas (GARBOSSA; PINHEIRO, 2015; PEREIRA; KAYSER; COLLISCHONN, 2012; WOLFF; DUARTE; MINGOTI, 2014; SABOIA; LOPARDO, 2015)

A identificação da relação entre as demandas, as atividades associadas aos usos em uma bacia, e a disponibilidade água para supri-las, são fundamentais para o estabelecimento de um bom diagnóstico de recursos hídricos que fornecerá suporte à gestão da água. A dinâmica econômica regional acompanha as tendências de disponibilidade e qualidade das águas ao longo do tempo. 0 crescimento de atividades poluidoras sem o controle adequado por exemplo, pode provocar degradação da qualidade das águas, ou inversamente, a diminuição das mesmas refletirá em melhorias (AGÊNCIA NACIONAL DE ÁGUAS, 2017).

0 crescimento populacional, aumento nas demandas referentes à atividades econômicas de grande intensidade de uso da água alimenta o chamado stress hídrico. Na Região Hidrográfica Atlântico Nordeste Oriental por exemplo é de grande expressão o uso da água em lavouras inundadas de arroz e, também pelas características semiáridas, é a região de maior estresse hídrico no Brasil. Olhando para a qualidade, os trechos mais comprometidos são aqueles nas proximidades de regiões metropolitanas onde os índices de Oxigênio Dissolvido são mínimos e as concentrações de Demanda Bioquímica de Oxigênio muito elevadas (AGÊNCIA NACIONAL DE ÁGUAS, 2018).

Segundo Silva e Monteiro (2003), para que se tenha um controle qualitativo e quantitativo dos usos da água, é fundamental conhecer os impactos quali-quantitativos de cada usuário, e principalmente a avaliação conjunta de tais impactos sobre o corpo hídrico Logo, a gestão dos recursos hídricos deve olhar para os aspectos de qualidade e quantidade associados, estendendo-se também aos usos minoritários. Esses não devem ser desprezados, em especial em bacias de pequeno porte, nas quais os usos insignificantes podem corresponder a uma fração importante das outorgas e gerar conflitos ou restrições (MARCOLINI, 2016).

O objetivo deste estudo foi de realizar um diagnóstico para identificar e quantificar os tipos de usos que recebem outorgas e dispensas de outorga por seus usos insignificantes no Estado do Paraná. O enfoque na avaliação foi os impactos gerados por usuários cadastrados e dispensados de outorgas em pequenas bacias hidrográficas.

\section{MATERIAIS E MÉTODOS}

Para os propósitos desta pesquisa os dados públicos de outorga do estado do Paraná disponibilizados até a data de 12 de dezembro de 2017 foram obtidos no website do Instituto das Águas do Paraná (INSTITUTO DAS ÁGUAS DO PARANÁ, 2017). Os dados considerados foram os de Outorga de Captação, Outorga de Lançamento de Efluentes, Cadastro de Usuários Dispensados de Outorga para o Lançamento de efluentes e Cadastro de Usuários Dispensados de Outorga para a Captação.

O tratamento das informações exigiu uma validação preliminar. Apenas os dados de captações superficiais foram considerados. Todos os dados desprovidos de coordenadas de localização foram excluídos. Consideraram-se apenas as outorgas vigentes ou em processo de renovação, sendo que estas informações foram agrupadas e tratadas a partir deste momento simplesmente por outorga. Os dados e as categorias consideradas para avaliação são apresentadas quantitativamente na Tabela 2 e sua distribuição espacial na Figura 1.

Tabela 2 - Dados considerados para avaliação.

\begin{tabular}{c|c}
\hline \multicolumn{1}{c}{ Classificação } & Quantidade \\
\hline Outorga de Captação em Rio & 1.307 \\
\hline Dispensa de Outorga de Captação em Rio & 2.381 \\
\hline Outorga de Lançamento de Efluentes & 606 \\
\hline Dispensa de Outorga de Lançamento de Efluentes & 60 \\
\hline
\end{tabular}




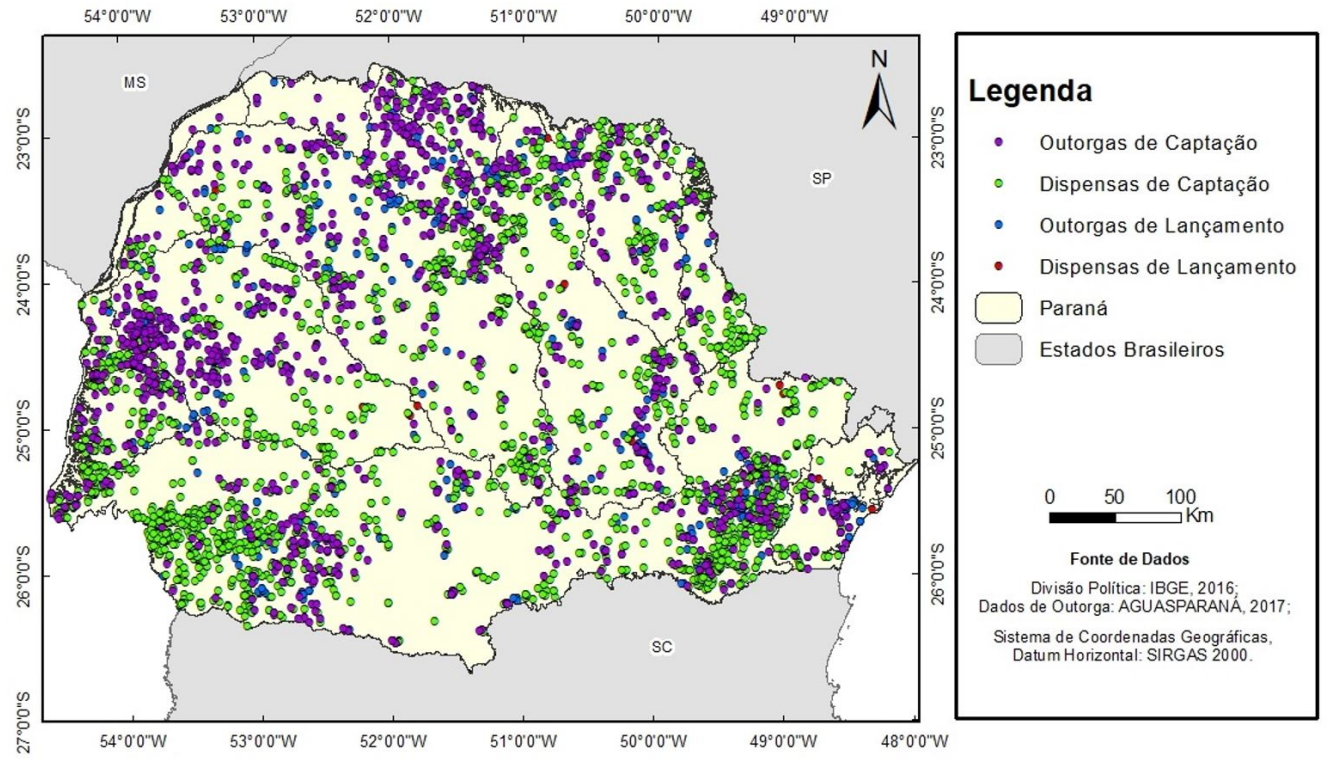

Figura 1 - Mapa dos dados de outorga (vigentes ou em renovação) bem como cadastros de usuários dispensados de outorga do Paraná até 12/12/2017 (INSTITUTO DAS ÁGUAS DO PARANÁ, 2017).

\section{Diagnóstico das Outorgas}

O diagnóstico dos dados consistiu em apresentar a distribuição por bacia hidrográfica dos usos e finalidades das outorgas de captação e lançamento de efluentes, bem como das dispensas de captação. As dispensas para o lançamento de efluentes não foram contempladas nesse diagnóstico por se tratar de um número reduzido de representantes em todo Estado (60 no total, Tabela 2), impossibilitando a identificação dos padrões de uso nas bacias.

\section{Efeito dos usos insignificantes}

Para verificar o efeito das dispensas para usos insignificantes, selecionou-se 15 bacias hidrográficas com área de drenagem inferior a $150 \mathrm{~km}^{2}$ em todo o estado do Paraná. Como premissa, a bacia hidrográfica deveria conter cadastros de dispensas de outorga e outorgas, possibilitando assim a quantificar os usos insignificantes em relação às outorgas nessas bacias hidrográficas. Buscando uma melhor distribuição espacial, definiu-se também como critério de seleção das pequenas bacias hidrográficas para o estudo, a busca de pelo menos uma representante em cada uma das grandes bacias hidrográficas do Paraná. A Figura 2 apresenta a localização das bacias hidrográficas de pequeno porte selecionadas para estudo.

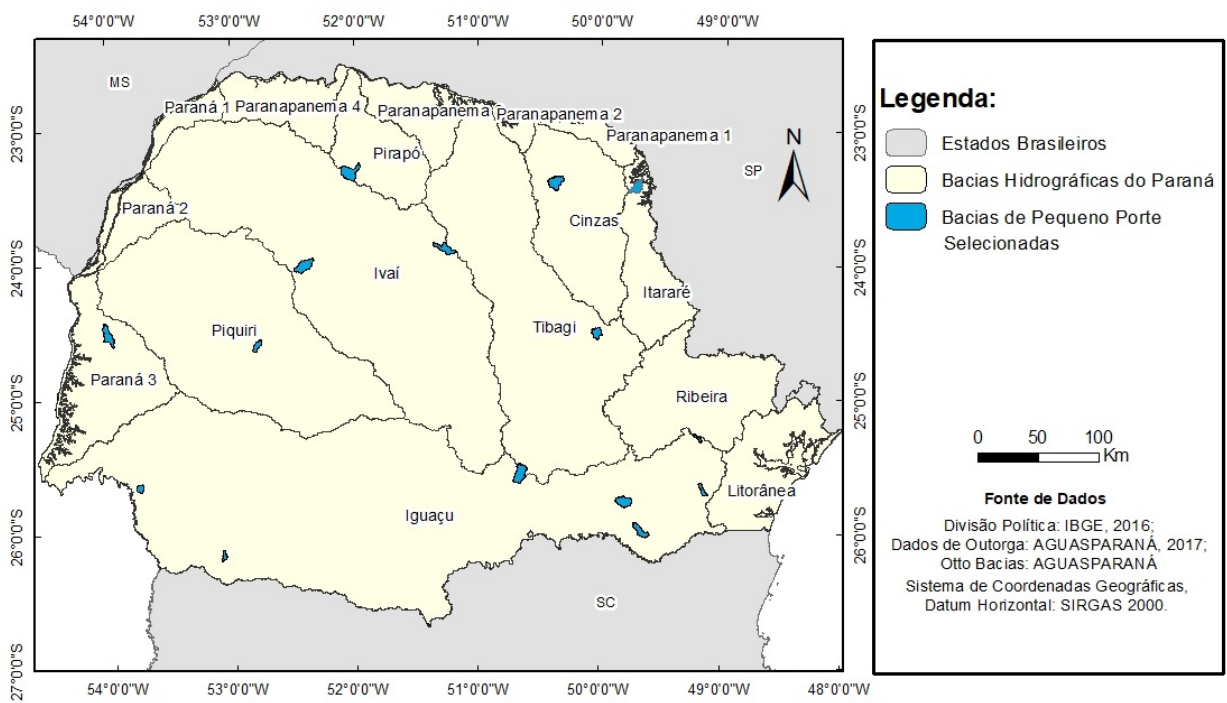

Figura 2 - Bacias de pequeno porte selecionadas para avaliar efeito dos usos insignificantes. 
Em cada uma das 15 bacias hidrográficas selecionadas, efetuou-se o cálculo da vazão outorgável correspondente a $50 \%$ da Q95\%, que é a vazão de referência correspondente a vazão natural com permanência de 95\% do tempo na seção. Para determinar a q95\% dois métodos foram utilizados. No primeiro a vazão de referência é baseada no Plano Diretor de Agricultura Irrigada - PDAI (INSTITUTO DAS ÁGUAS DO PARANÁ, 2012) que apresenta um mapa com as vazões de permanência específicas q95\% em L/s.km² para distintas áreas estratégicas de gestão. A informação foi extraída por identificação visual no mapa e como premissa conservadora o menor valor do intervalo de classe foi considerado.

O segundo método utilizado foi mediante o software Regionaliza 2014 (SABOIA; LOPARDO, 2015), que opera com um sistema de geração de variáveis hidrológicas para qualquer região paranaense. 0 programa utiliza dados históricos de estações de monitoramento com pelo menos 10 anos de registros, e possibilita a obtenção de diversos resultados hidrológicos como curvas de permanência, vazões máximas e mínimas, hidrograma de cheias, entre outros, a partir do informe da localização da exutória da bacia hidrográfica de interesse. Sua utilização é indicada para bacias hidrográficas com área de drenagem inferior a $5000 \mathrm{~km}^{2}$. A entrada da localização se deu na forma de coordenadas geográficas em WGS 84. Feita a regionalização extraiu-se da curva de permanência a vazão específica de referência q95\%.

Não houve avaliação qualitativa das dispensas para o lançamento de efluentes, uma vez que existem apenas 60 representantes em todo o Paraná. Desta forma, não foram identificadas bacias de pequeno porte que contenham um número significativo de representantes dos usos insignificantes no lançamento de efluentes. Por muitas vezes esse tipo de dispensa não existe nessas bacias. Consequentemente, essas dispensas, quando identificadas, foram apenas avaliadas quanto a disponibilidade hídrica, já que a análise da interferência delas sobre a qualidade foi inviabilizada pelo número inexpressivo de representantes em todo o estado.

\section{RESULTADOS E DISCUSSÃO}

A Figura 3 apresenta os pontos de outorga de captação no estado do Paraná e as distribuições dos usos a que são destinadas essas captações. Essas outorgas são distribuídas em todas as bacias hidrográficas do Estado, com algumas regiões de maior concentração. As captações na maioria das bacias hidrográficas paranaenses são utilizadas essencialmente na agropecuária, com exceção das bacias Litorânea, do Itararé e do Ribeira. Na bacia hidrográfica Litorânea, por exemplo, os usos mais relevantes refletem a característica regional onde o turismo é explorado e a agropecuária pouco desenvolvida (SECRETARIA DE ESTADO DO MEIO AMBIENTE E RECURSOS HÍDRICOS, 2010), consequentemente a maioria das captações se destinam ao saneamento. A bacia do Rio Itararé também tem seus usos voltados especialmente ao abastecimento da população. Já a do Rio Ribeira, tem suas captações utilizadas sobretudo no setor industrial que por sua vez está ligado aos sistemas de produção de leite, agroflorestal e de fruticultura presentes na região (SECRETARIA DE ESTADO DO MEIO AMBIENTE E RECURSOS HÍDRICOS, 2010).

A Figura 4 ilustra a distribuição dos usos das dispensas de captação. Observa-se que a bacia hidrográfica Litorânea atribui suas poucas dispensas de captação principalmente ao comércio e serviços, características do potencial turístico da região (SECRETARIA DE ESTADO DO MEIO AMBIENTE E RECURSOS HÍDRICOS, 2010). As demais bacias hidrográficas paranaenses fazem esse destino majoritariamente à agropecuária, sendo que a bacia do Iguaçu engloba o maior número dessas dispensas de captação (1002 dispensas, 42\% do total). 


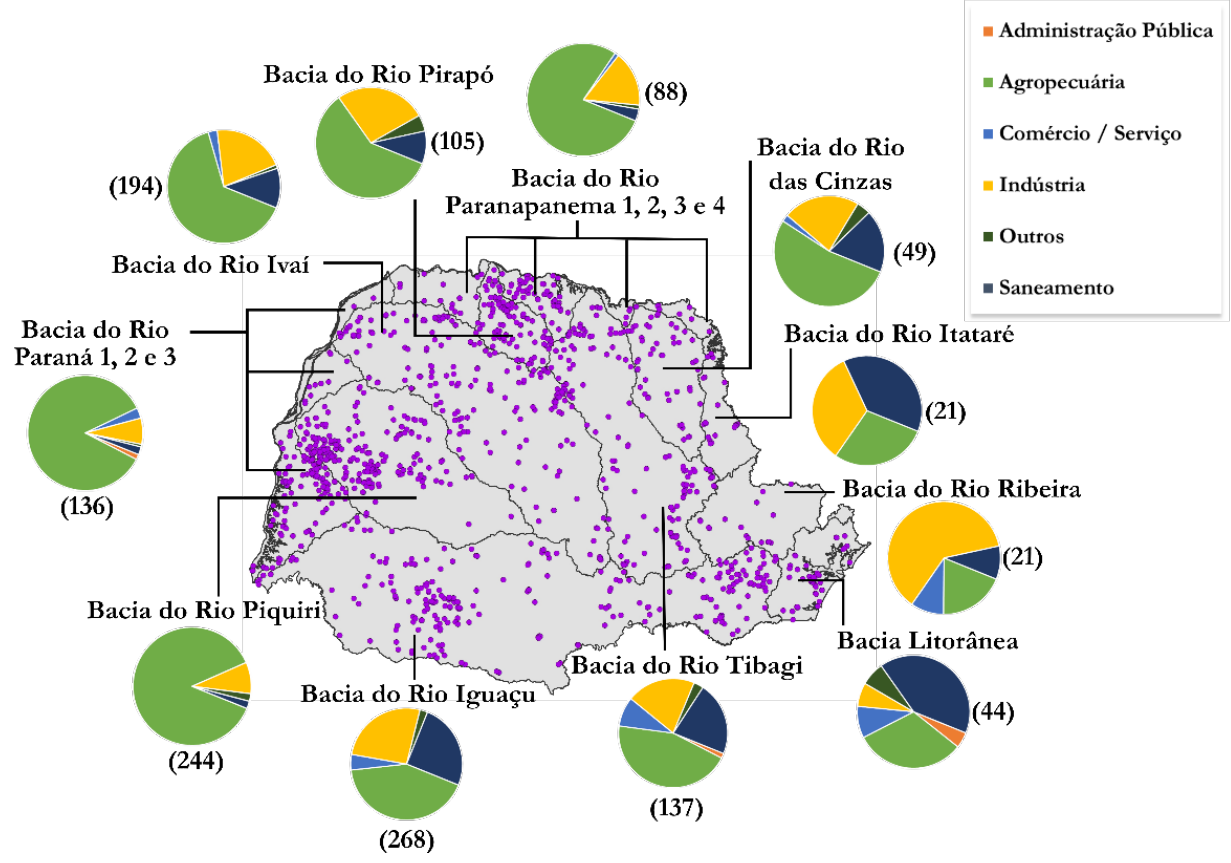

Figura 3 - Tipos de usos das outorgas de captação por bacia hidrográfica.

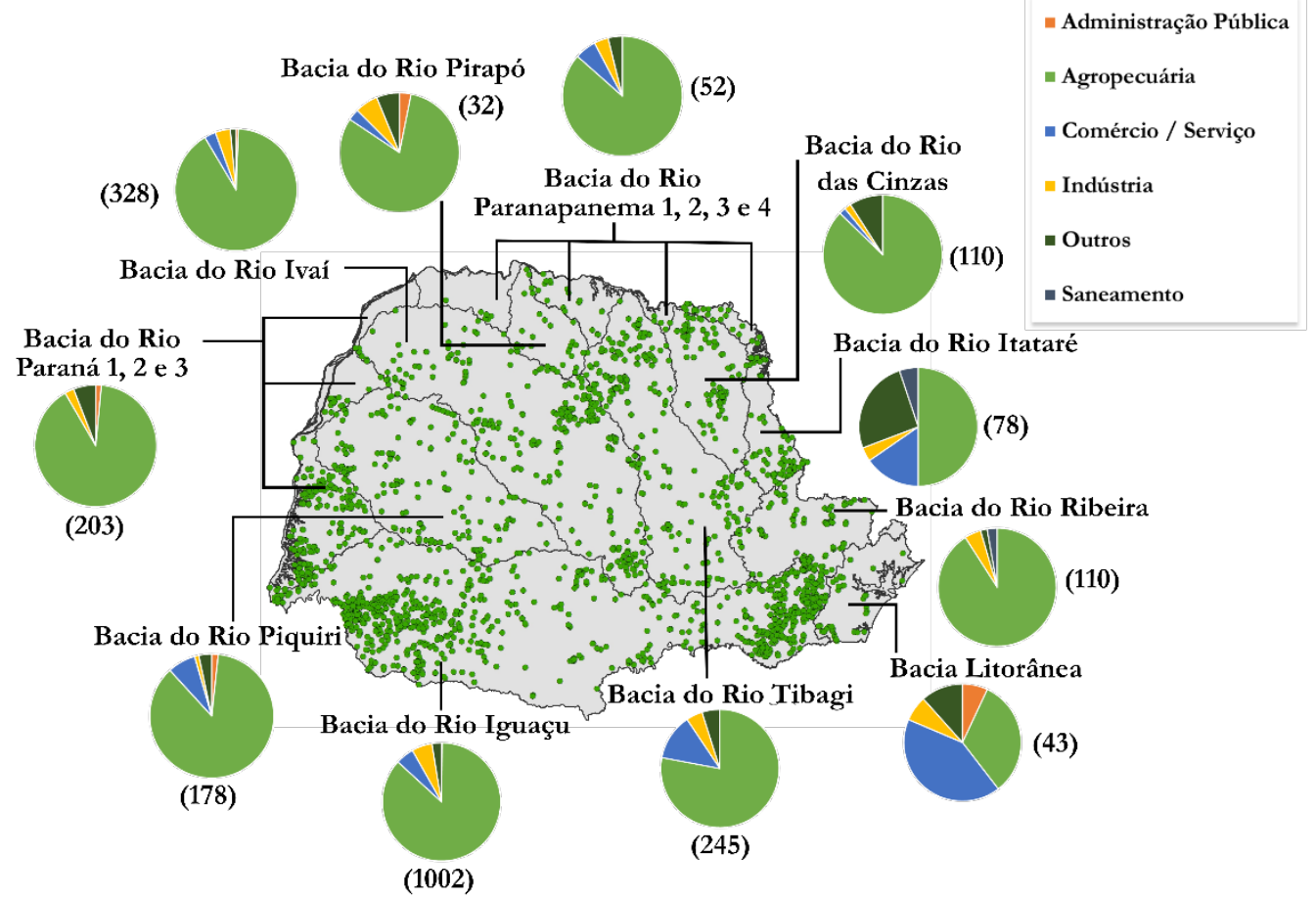

Figura 4 - Tipos de usos das dispensas de captação por bacia hidrográfica. 


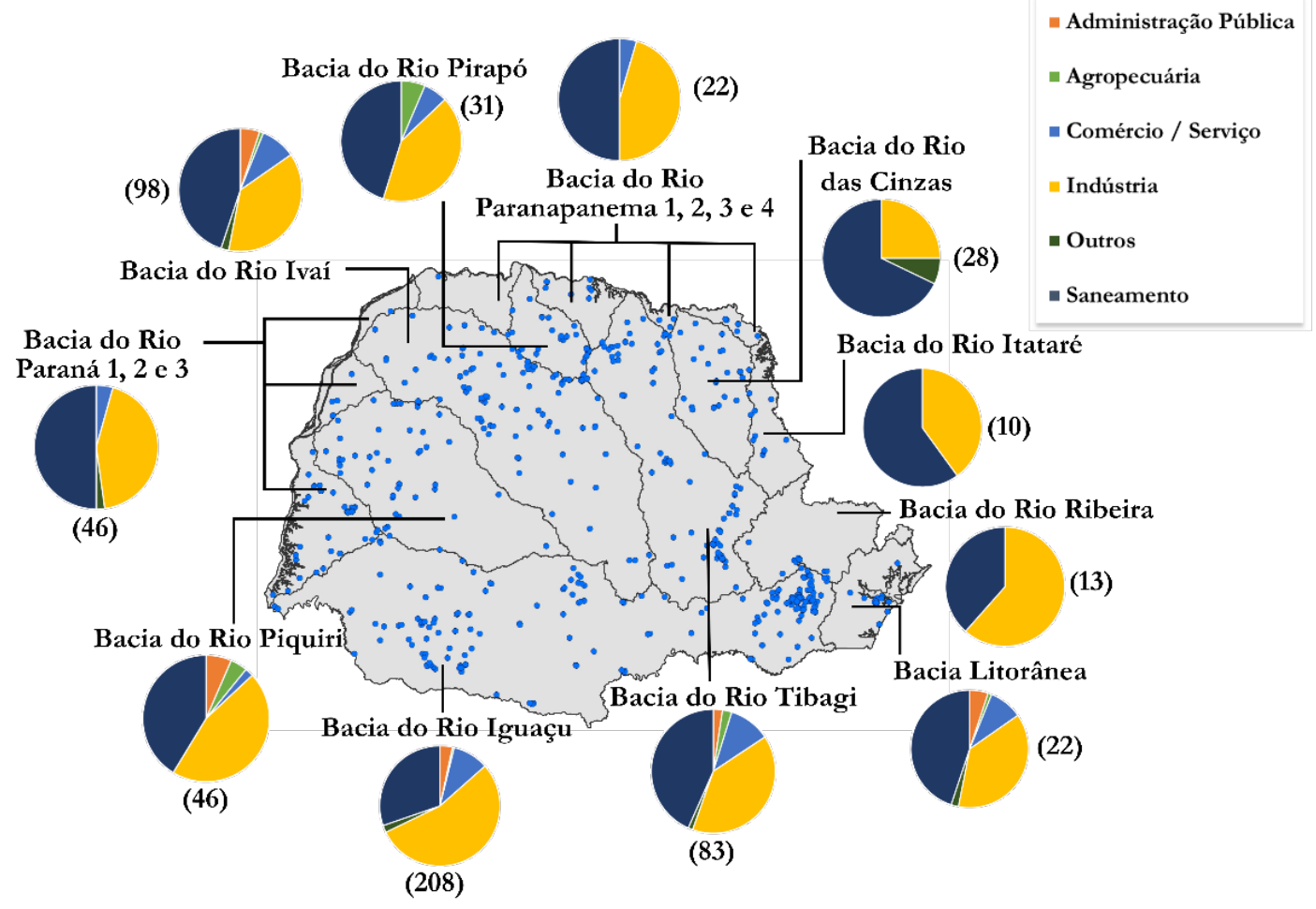

Figura 5 - Tipos de usos das outorgas de lançamento por bacia hidrográfica.

Na Figura 5, exibem-se os tipos de usos que são destinados a outorga de lançamento de efluentes, e também aqueles de maior relevância em cada bacia hidrográfica. Devido ao seu tamanho e pela densidade populacional, a bacia hidrográfica do rio Iguaçu concentra o maior número de outorgas para lançamento de efluentes no Paraná (208 outorgas, 34\% do total), sendo estas reservadas principalmente a processos industriais. Com a mesma destinação estão as bacias hidrográficas do Ribeira e Piquiri. No restante do Estado há a prevalência de outorgas de lançamento para o saneamento.

Os usos insignificantes que geram dispensas de captação são dominantes em termos de captação, correspondend o a 64,6\% das outorgas (Tabela 2). Em contrapartida, as dispensas representam apenas $9 \%$ das outorgas para lançamento de efluentes (Tabela 2), sendo desconsiderados para análises. Neste contexto, há uma potencial influência dos usos insignificantes na captação, apesar da vazão individual de cada outorga estar restrita ao um valor máximo de $0,5 \mathrm{~L} / \mathrm{s}$.

A Tabela 3 apresenta o percentual dos usos insignificantes em relação ao total das outorgas bem como sua relação à vazão outorgável para 15 bacias hidrográficas distribuídas no estado do Paraná. As bacias com áreas que variam de 29 a $127 \mathrm{~km}^{2}$ apresentam dispensas representando de 1,6 a 100\% da vazão outorgada.

Considerando os dois métodos aplicados para determinação da vazão de referência $\left(Q_{95 \%}\right)$ observou-se que as dispensas corresponderam de 0,7 a 15,7\% da vazão outorgável pelo método do PDAI e de 0,7 a 8,4\% pelo software Regionaliza 2014. A Figura 6 apresenta a relação entre as vazões de referência determinadas por cada método, sugerindo diferenças entre as estimativas, que não foram alvo de investigação, mas que provavelmente estão associadas à maior disponibilidade de dados para a regionalização realizada conforme Saboia e Lopardo (2015) e que para bacias com área menor do que $100 \mathrm{~km}^{2}$ os resultados devem ser vistos com reservas. Segundo Kaviski et al. (2002), há uma sensível falta de dados de bacias hidrográficas com menos de $100 \mathrm{~km}^{2}$, e os resultados nesse extremo são estimados por extrapolações.

A despeito das incertezas associadas ao método de obtenção das vazões de referência já destacado por Garbossa e Pinheiro (2015) e das diferenças entre métodos, o percentual dos usos insignificantes com relação à vazão outorgável é inferior a 15,7\% da disponibilidade hídrica. Assim, mesmo considerando o método mais conservador, dentre os dois apresentados, para a determinação das vazões de referência, os usos insignificantes não representam uma restrição para a disponibilidade hídrica do Paraná. 
Tabela 3 - Resumo das bacias selecionadas e comparação das vazões de referência para cada uma delas.

\begin{tabular}{|c|c|c|c|c|c|c|c|}
\hline \multirow[b]{2}{*}{ Bacia } & \multirow[b]{2}{*}{$\begin{array}{l}\text { Área } \\
\left(\mathrm{km}^{2}\right)\end{array}$} & \multirow[b]{2}{*}{$\begin{array}{c}Q_{\text {dispensas }} \\
(\mathrm{L} / \mathrm{s})\end{array}$} & \multirow{2}{*}{$\begin{array}{c}\text { Fração } \\
\text { das } \\
Q_{\text {dispensas }}\end{array}$} & \multicolumn{2}{|r|}{ PDAI } & \multicolumn{2}{|c|}{ Regionaliza 2014} \\
\hline & & & & $\begin{array}{l}Q_{\text {Outorgávei }} \\
(\mathrm{L} / \mathrm{s})\end{array}$ & $\begin{array}{c}\text { Fração dos } \\
\text { usos } \\
\text { insignificantes } \\
\end{array}$ & $\begin{array}{c}Q_{\text {Outorgável }} \\
(\mathrm{L} / \mathrm{s})\end{array}$ & $\begin{array}{c}\text { Fração dos } \\
\text { usos } \\
\text { insignificantes }\end{array}$ \\
\hline Rio da Campina & 29,96 & 3,49 & $9,9 \%$ & 92,43 & $3,8 \%$ & 80,46 & $4,3 \%$ \\
\hline $\begin{array}{c}\text { Campo do } \\
\text { Tenente }\end{array}$ & 66,55 & 3,00 & $16,4 \%$ & 131,44 & $2,3 \%$ & 104,19 & $2,9 \%$ \\
\hline Rio das Antas & 81,47 & 2,00 & $19,6 \%$ & 160,90 & $1,2 \%$ & 114,80 & $1,7 \%$ \\
\hline Itararé Sem nome & 75,36 & 2,00 & $5,5 \%$ & 232,50 & $0,9 \%$ & 87,74 & $2,3 \%$ \\
\hline Rio Tumiri & 16,13 & 5,00 & $100 \%$ & 31,85 & $15,7 \%$ & 82,96 & $6,0 \%$ \\
\hline Rio Riozinho & 108,59 & 1,50 & $5,8 \%$ & 214,47 & $0,7 \%$ & 196,06 & $0,8 \%$ \\
\hline Rio Vinte e Tres & 107,09 & 3,50 & $1,9 \%$ & 211,50 & $1,7 \%$ & 472,64 & $0,7 \%$ \\
\hline Córrego Saltinho & 28,34 & 3,50 & $12,3 \%$ & 55,97 & $6,3 \%$ & 114,08 & $3,1 \%$ \\
\hline Mandurira & 22,55 & 2,50 & $100 \%$ & 44,54 & $5,6 \%$ & 29,69 & $8,4 \%$ \\
\hline Ribeirão Atlântico & 126,88 & 2,50 & $7,7 \%$ & 250,59 & $1,0 \%$ & 254,38 & $1,0 \%$ \\
\hline Sem nome cinzas & 97,26 & 1,50 & $4,6 \%$ & 76,35 & $2,0 \%$ & 137,61 & $1,1 \%$ \\
\hline Passa Dois & 86,57 & 4,00 & $5,3 \%$ & 170,98 & $2,3 \%$ & 295,13 & $1,4 \%$ \\
\hline Quatro pontes & 92,25 & 2,00 & $1,6 \%$ & 284,59 & $0,7 \%$ & 277,41 & $0,7 \%$ \\
\hline $\begin{array}{l}\text { Água da } \\
\text { Penumbra }\end{array}$ & 37,39 & 1,50 & $6,3 \%$ & 73,85 & $2,0 \%$ & 162,50 & $0,9 \%$ \\
\hline Rio Piraí Mirim & 55,34 & 1,00 & $2,1 \%$ & 109,29 & $0,9 \%$ & 82,47 & $1,2 \%$ \\
\hline
\end{tabular}

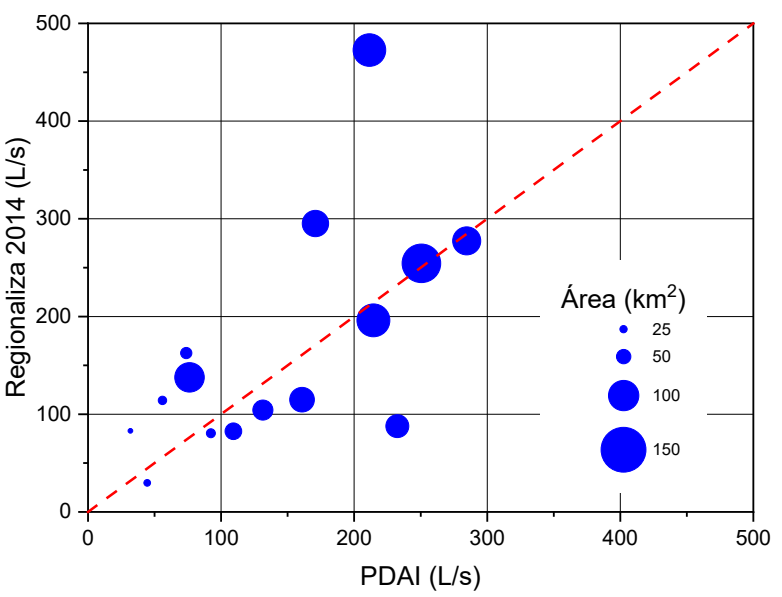

Figura 6 - Relação entre as vazões de referência determinadas pelos métodos Regionaliza 2014 e PDAI para as 15 bacias selecionadas no estudo em função de sua área de drenagem.

\section{CONCLUSÕES}

Os dados das outorgas de uso da água representam um reflexo da economia tanto do estado como das grandes bacias hidrográficas. No Paraná, as outorgas e dispensas confirmaram o domínio econômico do setor agropecuário e industrial. 0 diagnóstico reflete a importância das captações para fins agrícolas, e dos lançamentos de efluentes provenientes de processos industriais e de saneamento, já que essas são as atividades de maior demanda. 0 diagnóstico pode orientar os esforços de fiscalização e controle destes usos em cada região.

Como ferramenta de auxílio à gestão, ainda que neste caso os dados tenham sido obtidos por extrapolações (KAVISKI et al, 2002), a utilização do software Regionaliza 2014 (SABOIA; LOPARDO, 2015) para a obtenção das vazões naturais de permanência em $95 \%$ do tempo na seção do corpo hídrico, é indicada por contemplar dados atualizados de vazões e pela obtenção da informação de forma pontual, no exutório de interesse. Deste modo, apresenta como resultado dados específicos para o local de interesse ao invés de uma abordagem geral como nas áreas estratégicas de gestão do PDAI (INSTITUTO DAS ÁGUAS DO PARANÁ, 2012) contribuindo com maior confiabilidade de que a qualidade e a quantidade de água serão conservadas, assegurando esse recurso para as gerações futuras, como previsto na Lei das Águas (BRASIL, 1997). 
Em relação às dispensas de lançamento de efluentes, o número reduzido em todo o Estado, 60 no total, demonstra o cuidado criterioso de controle do órgão gestor na emissão destas dispensas, de modo que seu efeito potencialmente seja pequeno sobre os aspectos de qualidade dos recursos hídricos.

Sob o enfoque nos usuários presentes em pequenas bacias hidrográficas, como córregos e rios de baixa vazão, e as dispensas presentes nesses locais, verificou-se que as dispensas de captação associadas aos usos insignificantes correspondem à maior parcela das outorgas. A fração dos usos insignificantes em relação à vazão outorgável em bacias de pequeno porte no estado do Paraná revelou que as dispensas de outorga em geral não se caracterizam como um problema para a disponibilidade. Mesmo diante do fato de que os usos insignificantes representarem o maior número de usuários, estes exercem influência, em média, inferior a 3\% da vazão outorgável nas bacias analisadas, considerando o método mais conservador para determinação das vazões de referência.

Neste contexto, entende-se que a gestão de recursos hídricos no Paraná se mostra adequada com relação ao tratamento dos usos insignificantes dispensados de outorga.

\section{REFERÊNCIAS BIBLIOGRÁFICAS}

AGÊNCIA NACIONAL DE ÁGUAS - ANA. Cadernos de Capacitação em Recursos Hídricos - Outorga de Direito de Uso de Recursos Hídricos. Brasília: ANA, 2011. V. 6. ISBN 978-85-89629-78-2.

AGÊNCIA NACIONAL DE ÁGUAS - ANA. Conjuntura dos recursos hídricos no Brasil 2017: relatório pleno. Agência Nacional de Águas, Brasília, 2017.

AGÊNCIA NACIONAL DE ÁGUAS - ANA. Conjuntura dos recursos hídricos no Brasil 2018: informe anual. Brasília: Agência Nacional de Águas, 2018.

BRASIL. Lei n. 9.433 de 8 de janeiro de 1997. Institui a Política Nacional de Recursos Hídricos, cria o Sistema Nacional de Gerenciamento de Recursos Hídricos, regulamenta o inciso XIX do art. 21 da Constituição Federal, e altera o art. 1 o da Lei no 8.001, de 13 de março de 1990, que modificou a Lei no 7.990, de 28 de dezembro de 1989.

CEARÁ. Decreto $N^{\circ} 23.067$, de 11 de fevereiro de 1994. Regulamenta o artigo $4^{\circ}$ da Lei No 11. 996, de 24 de julho de 1992, na parte referente à outorga do direito de uso dos recursos hídricos, cria o Sistema de Outorga para Uso da Água e dá outras providências. Regulamenta o artigo $4^{\circ}$ da Lei ${ }^{\circ} 11.996$, de 24 de julho de 1992, na parte referente à outorga do direito de uso dos recursos hídricos, cria o Sistema de Outorga para Uso da Água e dá outras providências.

CONSELHO ESTADUAL DE RECURSOS HÍDRICOS - CERH. Deliberação Normativa do Conselho Estadual de Recursos Hídricos - MG $n^{\circ}$ 09, de 16 de junho de 2004. Minas Gerais. Define os usos insignificantes para as circunscrições hidrográficas no Estado de Minas Gerais.

CONSELHO ESTADUAL DE RECURSOS HÍDRICOS DE SERGIPE - CONERH/SE. Resolução no 01/2001 de 19 de abril de 2001. Dispõe sobre critérios para a outorga de uso de recursos hídricos.

GARBOSSA, L. H. P.; PINHEIRO, A. Vazões de referência para gestão de bacias hidrográficas rurais e urbanas sem monitoramento. REGA: Revista de Gestão de Águas da América Latina, v. 12, n. 1, p. 43-52, 2015.

HODGSON, S. Modern water rights: theory and practice. Food \& Agriculture Org., 2006.

INSTITUTO DAS ÁGUAS DO PARANÁ - AGUASPARANÁ. Plano Diretor de Agricultura Irrigada - PDA. 2012

INSTITUTO DAS ÁGUAS DO PARANÁ - AGUASPARANÁ. Dados para Download. 2017. Dados de Outorgas do Estado do Paraná. Disponível em:

<http://www.aguasparana.pr.gov.br/modules/conteudo/conteudo.php?conteudo=79>. Acesso em: $12 \mathrm{dez}$. 2017.

KAVISKI, E. et al. (2002) Atualização do método de Regionalização do Projeto HG-77. Curitiba: LACTEC. v. 3, 66 p. Relatório Técnico.

MACHADO, E. C. M. N.; GALVÃO, C. O.; SOUZA FILHO, F. A. Alocação quali-quantitativa da alocação de água em bacias hidrográficas: metodologia multiobjetiva inserida no contexto de recursos hídricos. Revista Brasileira de Recursos Hídricos, Porto Alegre, v. 17, p. 213-228, 2012.

MARCOLINI, F. C. P. A influência das captações de águas superficiais consideradas insignificantes na vazão do Ribeirão Água Fria. Dissertação. Universidade Federal do Tocantins, Palmas, 2016.

MOREIRA, M. C. et al. Índices de conflito pelo uso da água da bacia do ribeirão entre Ribeiros. Revista Brasileira de Recursos Hídricos, Porto Alegre, v. 19, n. 1, p. 221-228, 2014. 
PARAÍBA. Decreto no 19.260, de 31 de outubro de 1997. Regulamenta a Outorga do Direito de Uso dos Recursos Hídricos.

PEREIRA, M.; KAYSER, R. B.; COLLISCHONN, W. Integração do Modelo Hidrológico para Grandes Bacias MGB-IPH e Sistemas de Informação Geográfica para suporte à decisão de outorga de direito de uso da água. REGA: Revista de Gestão de Águas da América Latina, Porto Alegre, v. 9, n. 2, p. 21-33, 2012.

RIBEIRO, M. M. R.; LANNA, A. E. L. A outorga integrada das vazões de captação e diluição. Revista Brasileira de Recursos Hídricos, Porto Alegre, v. 8, n. 3, p. 151-168, 2003.

SABOIA, J. P. J.; LOPARDO, N. Software para cálculo de regionalização de parâmetros hidrológicos em bacias do estado do paraná. In: XXI Simpósio Brasileiro de Recursos Hídricos, nov. 2015.

SÃo PAULO. Departamento de Águas e Energia Elétrica - DAEE. Portaria DAEE n 1.631, de 30 de maio de 2017. 2017. Diário Oficial [do] Estado de São Paulo.

SECRETARIA DE ESTADO DO MEIO AMBIENTE E RECURSOS HÍDRICOS - SEMA. Resolução 039/2004 da Secretaria de Estado do Meio Ambiente e Recursos Hídricos, 2004.

SECRETARIA DE ESTADO DO MEIO AMBIENTE E RECURSOS HÍDRICOS - SEMA. Bacias Hidrográficas do Paraná. Governo do Estado do Paraná, 2010. Série Histórica.

SILVA, L. M. C.; MONTEIRO, R. A. Outorga de direito de uso de recursos hídricos: uma das possíveis abordagens. Gestão de águas doces: usos múltiplos, políticas públicas e exercício da cidadania no Brasil. Interciencia, Rio de Janeiro, p. 140-179, 2003.

SUPERINTENDÊNCIA DE RECURSOS HÍDRICOS DO ESTADO DA BAHIA - SRH. Instrução Normativa $n^{\circ} 01$, de 27 de fevereiro de 2007. Dispõe sobre a emissão de outorga de direito de uso dos recursos hídricos de domínio do Estado da Bahia, assim como a sua renovação, ampliação, alteração, transferência, revisão, suspensão e extinção, e dá outras providências.

VIEIRA, V. P. P. B. Desafios da gestão integrada de recursos hídricos no semi-árido. Revista Brasileira de Recursos Hídricos, Porto Alegre, v. 8, n. 2, p. 7-17, 2003.

WOLFF, W.; DUARTE, S. N.; MINGOTI, R. Nova metodologia de regionalização de vazões, estudo de caso para o Estado de São Paulo. Revista Brasileira de Recursos Hídricos, Porto Alegre, v. 19, n. 4, p. 21-33, 2014.

\section{Contribuições dos autores}

Camila Marin Stinghen: Contribuiu na redação, processamento e análise de dados e da elaboração gráfica.

Michael Mannich: Contribuiu na proposição da pesquisa, elaboração gráfica, redação e revisão do documento. 